\title{
Effects of cisatracurium on epithelial-to-mesenchymal transition in esophageal squamous cell carcinoma
}

\author{
WENYAN LV, JINGYU WANG and SHUBAO ZHANG
}

Department of Anesthesiology, Chinese People's Liberation Army No. 117 Hospital, Hangzhou, Zhejiang 310013, P.R. China

Received November 22, 2018; Accepted June 28, 2019

DOI: $10.3892 / \mathrm{ol} .2019 .10859$

\begin{abstract}
Esophageal squamous cell carcinoma (ESCC) is one of the most aggressive types of cancer worldwide, with a poor prognosis. The aim of the present study was to investigate the effect of cisatracurium (Cis) on epithelial-to-mesenchymal transition (EMT) in ESCC and its potential mechanism of action. In the present study, Cis was used to treat ECA-109 cells, with cell proliferation measured by a Cell Counting Kit- 8 assay and the expression of TGF- $\beta$ and phospho-Smad $2 / 3$ detected by western blotting. TGF- $\beta$ was then applied to induce EMT. Flow cytometry, wound healing and Transwell assays were used to evaluate cell proliferation, apoptosis, invasion and migration. In addition, cell cycle-related proteins, including cyclin D1, p53 and p21, and EMT-associated proteins, including E-cadherin (E-cad), N-cadherin (N-cad), Vimentin and Slug, were examined by western blot analysis. The results revealed that Cis inhibited the proliferation and promoted apoptosis of ESCC cells. Following treatment with Cis, the expression of TGF- $\beta$ and phosphorylation of Smad $2 / 3$ were downregulated. Cis also suppressed cancer cell invasion and migration induced by TGF- $\beta$. In addition, the expression levels of cyclin D1 were decreased, accompanied by increased p53 and p21 expression. In addition, the expression level of E-cad was increased, whereas N-cad, Vimentin and Slug were significantly reduced. Taken together, the results of the present study revealed that exposure of ESCC cells to Cis inhibited EMT and reduced cell invasion and metastasis through the TGF- $\beta$ /Smad signaling pathway.
\end{abstract}

\section{Introduction}

Esophageal squamous cell carcinoma (ESCC) is one of the most common and deadliest malignancies worldwide, with the incidence and mortality rates increasing annually $(1,2)$.

Correspondence to: Dr Wenyan Lv, Department of Anesthesiology, Chinese People's Liberation Army No. 117 Hospital, 14 Lingyinsi Road, Hangzhou, Zhejiang 310013, P.R. China

E-mail: lvwenyan996@163.com

Key words: esophageal squamous cell carcinoma, cisatracurium, invasion, epithelial-to-mesenchymal transition
Despite rapid advances in multiple therapies, the prognosis of ESCC remains poor due to its late diagnosis and extensive metastases (3). Dietary, lifestyle habits and genetic polymorphisms are currently considered as major factors affecting the occurrence and development of ESCC (4). For instance, alcohol intake can interact with functional genetic polymorphisms of aldehyde dehydrogenase and alcohol dehydrogenase to increase ESCC risk (5). In addition, genetic polymorphisms in the autophagy related 5 gene predict survival and recurrence in patients with early-stage ESCC (6). However, the potential molecular mechanisms underlying ESCC progression have not been fully elucidated.

Cell proliferation is crucial for cancer progression. A critical tumor suppressor gene, p53, is typically found to harbor mutations or deletions in several human malignancies, including ESCC (7,8); it can inhibit cell cycle progression by inducing p21 (9). Cyclin D1, a key regulator of G1-to-S-phase transition, is overexpressed and amplified in a many cancers, and it has been previously demonstrated that cyclin D1 enables progression from G1 to $\mathrm{S}$ phase of the cell cycle by binding and sequestering p21 (10).

Invasion and metastasis are hallmarks of cancer. Epithelial-to-mesenchymal transition (EMT) is a process during which epithelial cells lose their polarity and acquire a mesenchymal phenotype, which is a pivotal step towards cancer invasion and metastasis $(11,12)$. Activation of EMT is associated with aberrant expression of a variety of genes. It is commonly characterized by downregulation of E-cadherin (E-cad), which is a key epithelial marker, accompanied by upregulation of $\mathrm{N}$-cadherin (N-cad), Vimentin and Slug, which are crucial mesenchymal marker genes (13-15). The aforementioned changes lead to the induction of invasive and migratory properties in cancer cells. It has been well documented that transforming growth factor- $\beta$ (TGF- $\beta$ ) is one of the crucial factors that regulate the initiation and maintenance of EMT in a number of cancers (16). In addition, accumulating evidence shows that TGF- $\beta$ is implicated in EMT in several human malignancies, such as lung, gastric and ovarian cancer, as well as ESCC (16-19).

Muscle relaxants, including rocuronium and cisatracurium (Cis), effectively block the activation of muscles by nerves. Rocuronium has been shown to promote the invasion, adhesion and growth of MDA-231 breast cancer cells (20). It was previously reported that propofol, which is one of the most common intravenous anesthetic agents used during cancer 
resection surgery, suppresses proliferation and invasion by downregulating ERK-vascular endothelial growth factor/matrix metallopeptidase-9 signaling in ECA-109 ESCC cells (21). Cis has been shown to inhibit the proliferation, invasion and migration of gastric cancer cells (22). In addition, emerging evidence indicates that $\mathrm{Cis}$ can suppress cancer cell proliferation, invasion and migration via upregulation of $\mathrm{p} 53$, and inhibits the aggressiveness of colorectal cancer (23). However, the role of Cis in the progression of ESCC has not been clearly determined.

The aim of the present study was to investigate the role of Cis in ESCC. The results revealed that exposure of ESCC cells to Cis inhibited TGF- $\beta$-induced EMT, and reduced cell invasion and metastasis through the TGF- $\beta /$ Smad signaling pathway.

\section{Materials and methods}

Cell culture. Human ECA-109 cells were purchased from the Type Culture Collection of the Chinese Academy of Science and incubated in DMEM (Gibco; Thermo Fisher Scientific, Inc.) containing 10\% FBS (Gibco; Thermo Fisher Scientific, Inc.) at $37^{\circ} \mathrm{C}$ with $5 \% \mathrm{CO}_{2}$.

Cell proliferation assay. The Cell Counting Kit-8 (CCK-8) assay (OBiO Technology, Corp., Ltd.) was employed to evaluate the proliferation response of ECA-109 cells treated with different concentrations of Cis (10, 20 and $30 \mathrm{mM}$; Nimbex; GlaxoSmithKline plc) (24), in accordance with the manufacturer's protocol. ECA-109 cells were seeded in 96-well plates $\left(5 \times 10^{3}\right.$ cells/well) and incubated at $37^{\circ} \mathrm{C}$ with $5 \% \mathrm{CO}_{2}$ for $24 \mathrm{~h}$. Subsequently, the cells were exposed to Cis at 10, 20 and $30 \mathrm{mM}$ for 24,48 and $72 \mathrm{~h}$. At the end of the exposure periods, $10 \mu \mathrm{l}$ CCK-8 solution was added to each well. Following incubation at $37^{\circ} \mathrm{C}$ for $1 \mathrm{~h}$, absorbance rate was measured at $490 \mathrm{~nm}$ using a plate reader.

Wound healing assay. For the scratch wound healing assay, Cis $(20 \mathrm{mM})$ alone or Cis $(20 \mathrm{mM})$ combined with TGF- $\beta$ (1 ng/ml; Sigma-Aldrich; Merck KGaA)-treated ECA-109 cells were plated in 12-well plates at a density of $1 \times 10^{5}$ cells/well. Once cells reached $80 \%$ confluence, medium was replaced by serum-free DMEM and cells were incubated at $37^{\circ} \mathrm{C}$ overnight before initiating the experiment. A wound was created on the surface of the cell monolayer using a $200-\mu 1$ pipette tip. The cells were then rinsed twice with serum-free medium in order to remove free-floating cells and debris. An inverted microscope (magnification, x20; BX51; Olympus Corporation) was used to monitor cells at the edges of the scratch. The percentage of wound closure was determined according to the following equation: [(Ai-At)/Ai] x $100 \%$, where Ai represents the initial area of the wound at $0 \mathrm{~h}$ and At represents the area of the wound after $24 \mathrm{~h}$.

Cell invasion assay. To assess the effect of Cis on invasion of ECA-109 cells, 24-well Transwell plates (Corning, Inc.) with $8-\mu \mathrm{m}$ pore inserts coated with Matrigel (BD Biosciences). A total of $200 \mu \mathrm{l}$ serum-free medium ECA-109 cell suspension containing $5 \times 10^{5}$ cells $/ \mathrm{ml}$ was added to the upper chamber and $600 \mu \mathrm{l}$ DMEM containing $10 \%$ FBS was added to the lower compartment. After $24 \mathrm{~h}$ of incubation at $37^{\circ} \mathrm{C}$ with $5 \% \mathrm{CO}_{2}$, the Matrigel and the cells remaining in the upper chamber were removed by a cotton-tipped swab. The filters were fixed in $4 \%$ formaldehyde for $10 \mathrm{~min}$ at room temperature and stained with $0.1 \%$ crystal violet solution for $30 \mathrm{~min}$ at room temperature. The cells in five random fields (magnification, $\mathrm{x} 20$ ) were observed under an inverted microscope (Olympus Corporation).

Flow cytometry assay. The cell cycle distribution was examined using the Cell Cycle Analysis kit (Beyotime Institute of Biotechnology), according to the manufacturer's protocols. ECA-109 cells treated with Cis $(20 \mathrm{mM})$ or Cis $(20 \mathrm{mM})$ combined with TGF- $\beta$ ( $1 \mathrm{ng} / \mathrm{ml})$ for $48 \mathrm{~h}$, were treated with $70 \%$ cold ethanol at $4^{\circ} \mathrm{C}$ overnight to increase cell membrane penetrability. Subsequently, $100 \mu \mathrm{g} / \mathrm{ml}$ RNase (Nanjing KeyGen Biotech Co., Ltd.) was used to treat cells at $37^{\circ} \mathrm{C}$ for $20 \mathrm{~min}$. Following staining with $30 \mu \mathrm{g} / \mathrm{ml}$ propidium iodide (Nanjing KeyGen Biotech Co., Ltd.) for $30 \mathrm{~min}$ at room temperature in the dark, the cell cycle was analyzed using a Gallios Flow Cytometer (Beckman Coulter, Inc.). The flow cytometry results were evaluated using a Cell Quest kit (BD CellQuest $^{\mathrm{TM}}$ Pro software version 6.1; BD Biosciences), according to the manufacturer's protocols.

Cell apoptosis assay. ECA-109 cells were seeded into 6-well plates $\left(5 \times 10^{5} /\right.$ well) and incubated overnight at $37^{\circ} \mathrm{C}$ with $5 \%$ $\mathrm{CO} 2$. Cell apoptosis was determined by using the Annexin V-PE/7AAD Staining Cell Apoptosis Detection kit (Nanjing KeyGen Biotech Co., Ltd.), according to the manufacturer's protocols, and analyzed using FlowJo software (version10.5.2; Becton, Dickinson and Company).

Western blot analysis. ECA-109 cells were collected and lysed with RIPA lysis buffer (Beyotime Institute of Biotechnology) and incubated for $30 \mathrm{~min}$ on ice. Then proteins were detected using a BCA protein assay kit (Bio-Rad Laboratories, Inc.). A total of $40 \mu \mathrm{g}$ protein was loaded onto $10 \% \mathrm{SDS}$-polyacrylamide gels to separate various proteins, which were subsequently transferred to PVDF membranes. The membranes were blocked with $10 \%$ skimmed milk for $2 \mathrm{~h}$ at room temperature, followed by incubation with primary antibodies overnight at $4^{\circ} \mathrm{C}$. Subsequently, the membranes were incubated with goat anti-rabbit horseradish peroxidase-conjugated $\operatorname{IgG}$ secondary antibodies (1:2,000; cat. no. 4414s) at room temperature for $1 \mathrm{~h}$. The signals were detected using enhanced chemiluminescence reagent (GE Healthcare) and Image $\mathbf{J}$ software (version 146; National Institutes of Health) was used to analyze the fold-changes of protein levels. Anti-p-Smad2/3 (1:1,000; cat. no. $8828 \mathrm{~S})$, anti-Smad2/3 (1:1,000; cat. no. 8685S), anti-cyclin D1 (1:1,000; cat. no. 2978T), anti-p53 (1:1,000; cat. no. 2527T), anti-p21 (1:1,000; cat. no. 2947S), anti-E-cad (1:1,000; cat. no. 3195S), anti-N-cad (1:1,000; cat. no. 13116S), anti-Vimentin (1:1,000; cat. no. $5741 \mathrm{~S})$, anti-TGF- $\beta$ (1:1,000; cat. no. $3711 \mathrm{~s})$, anti-Slug $(1: 1,000$; cat. no. $9585 \mathrm{~T})$, anti- $\beta$-actin $(1: 1,000$; cat. no. 3700 s) and anti-GAPDH $(1: 1,000$; cat. no. $5174 \mathrm{~S})$ antibodies were obtained from Cell Signaling Technology, Inc.

Statistical analysis. Statistical data analysis was performed with SPSS 22.0 (IBM Corp.) and GraphPad Prism 5.0 (GraphPad Software, Inc.). All experimental results are expressed as mean \pm standard deviation. Each experiment was 

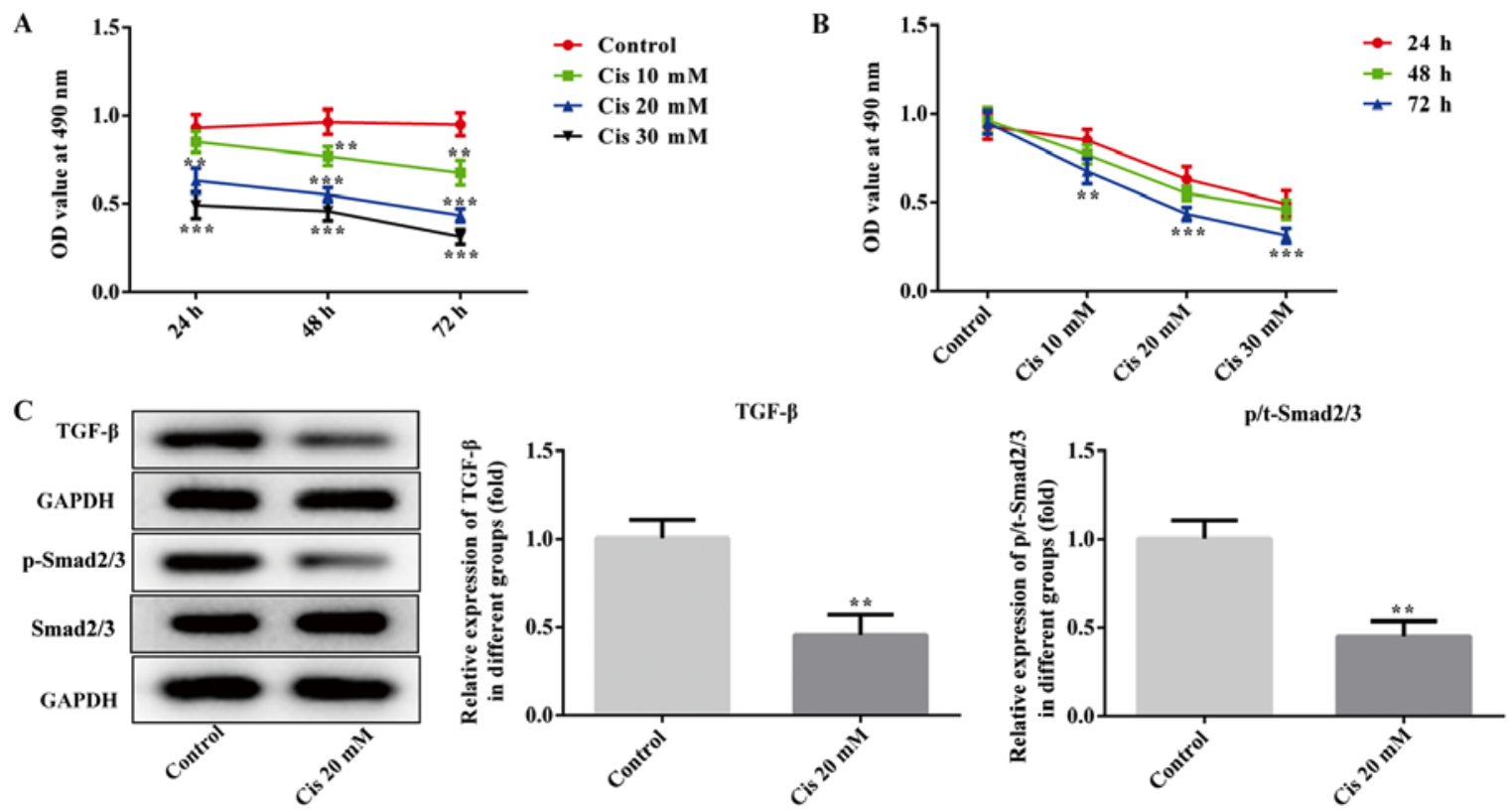

Figure 1. Proliferation of ESCC cells and the expression of TGF- $\beta$ and p-Smad $/ 3$ following treatment with Cis. The changes in ESCC cell proliferation according (A) concentration of Cis or (B) treatment time were measured by the CCK- 8 assay. (C) Expression levels of TGF- $\beta$ and p-Smad $2 / 3$ were evaluated by western blot analysis. ${ }^{* *} \mathrm{P}<0.01,{ }^{* * *} \mathrm{P}<0.001$ vs. control. ESCC, esophageal squamous cell carcinoma; TGF- $\beta$, transforming growth factor- $\beta$; CCK, Cell Counting $\mathrm{Kit}$; Cis, cisatracurium; OD, optical density.

repeated at least three times. Data were analyzed using either a ANOVA followed by a Tukey's post-hoc test for comparison of multiple groups or an independent Student's t-test for comparison of two groups. $\mathrm{P}<0.05$ was considered to indicate statistically significant differences.

\section{Results}

Cis treatment decreases the expression levels of TGF- $\beta$ and Smad2/3 in ESCC cells. The CCK-8 assay was used to determine the optimal time and concentration of Cis treatment. As shown in Fig. 1A and B, the ability of ESCC cells to proliferate decreased with the increase in the concentration of Cis. When ECA-109 cells were treated with $20 \mathrm{mM}$ Cis for $48 \mathrm{~h}$, cell viability was reduced by $\sim 50 \%$, therefore this dose was selected for further experiments. In addition, the expression of TGF- $\beta$ and $p-S m a d 2 / 3$ was significantly downregulated in the Cis $20 \mathrm{mM}$ group compared with the control $(\mathrm{P}<0.01$; Fig. 1C). These results indicated that Cis inhibited the proliferation of ESCC cells and regulated TGF- $\beta /$ Smad signaling.

Cis treatment inhibits proliferation and promotes apoptosis in TGF- $\beta$-treated ESCC cells. To further investigate the role of $\mathrm{Cis}$ in the proliferation and apoptosis of TGF- $\beta$-treated ESCC cells, flow cytometry was applied. The results suggested that the percentage of cells in the $\mathrm{S}$ phase in the Cis $20 \mathrm{mM}$ group was lower compared with that of the untreated group, while the opposite results were observed for the G0/G1 phase (Fig. 2A and C). After treating ESCC cells with $20 \mathrm{mM}$ Cis plus TGF- $\beta$, the number of cells in the $S$ phase increased, whereas that in the G0/G1 phase was notably decreased compared with treatment with Cis alone (Fig. 2A and C). Furthermore, the rate of cell apoptosis increased following Cis treatment, whereas the apoptotic cell number decreased following intervention with both Cis and TGF- $\beta$ (Fig. 2B and D). In addition, the expression of cyclin D1 was downregulated, accompanied by upregulated expression of p53 and p21 in the Cis $20 \mathrm{mM}$ group, while the level of cyclin D1 was increased, along with decreased levels of p53 and p21 following treatment with $20 \mathrm{mM}$ Cis plus TGF- $\beta$ (Fig. 2E and F). These data indicated that Cis treatment suppressed proliferation and promoted apoptosis in ESCC cells.

Cis treatment suppresses invasion and migration in TGF- $\beta$-treated ESCC cells. To evaluate invasion and migration in TGF- $\beta$-treated ESCC cells, the wound healing and Transwell assays were used in the present study. As shown in Fig. 3A and B, the ability of cell invasion was decreased by Cis compared with the control group; however, cell invasion was increased following treatment with both Cis and TGF- $\beta$. Moreover, the change in cell migration was consistent with the results on invasion (Fig. 3C and D). Therefore, Cis treatment inhibited invasion and migration in ESCC cells.

Cis treatment inhibits EMT in TGF- $\beta$-treated ESCC cells. The expression of EMT-related proteins was evaluated using western blot analysis. As shown in Fig. 4, the expression level of E-cad was increased, whereas the expression levels of N-cad, Slug and Vimentin decreased when ESCC cells were treated with Cis alone. Following treatment with TGF- $\beta$ plus Cis, the E-cad expression was reduced, accompanied by increased expression of N-cad, Slug and Vimentin compared with Cis treatment alone. These results indicated that Cis suppressed EMT in TGF- $\beta$-treated ESCC cells.

\section{Discussion}

Esophageal cancer is one of the most common cancers worldwide, and the majority of cases of esophageal cancer are 


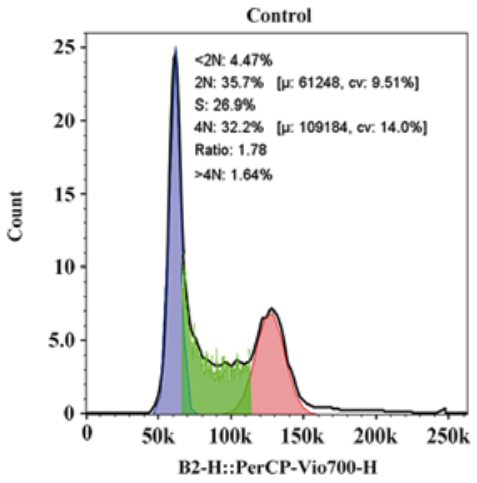

B

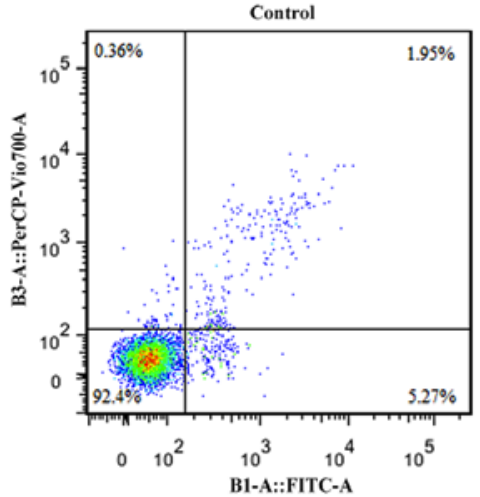

C
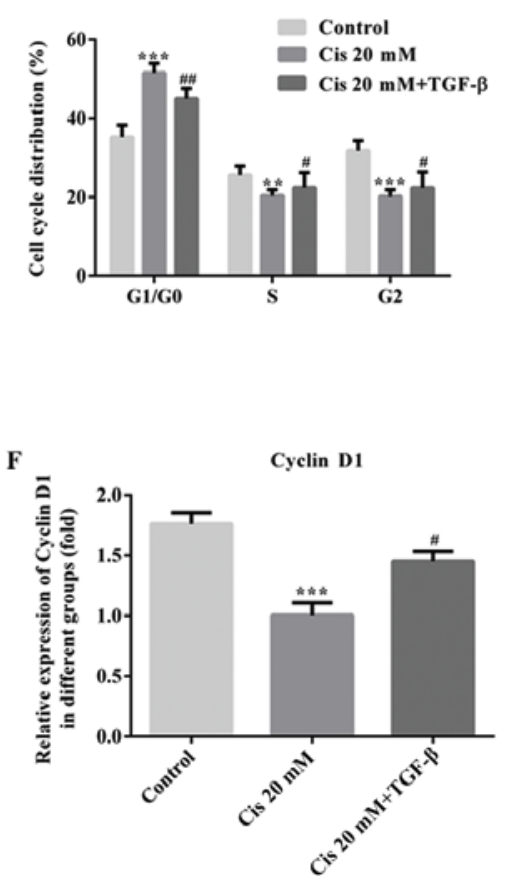
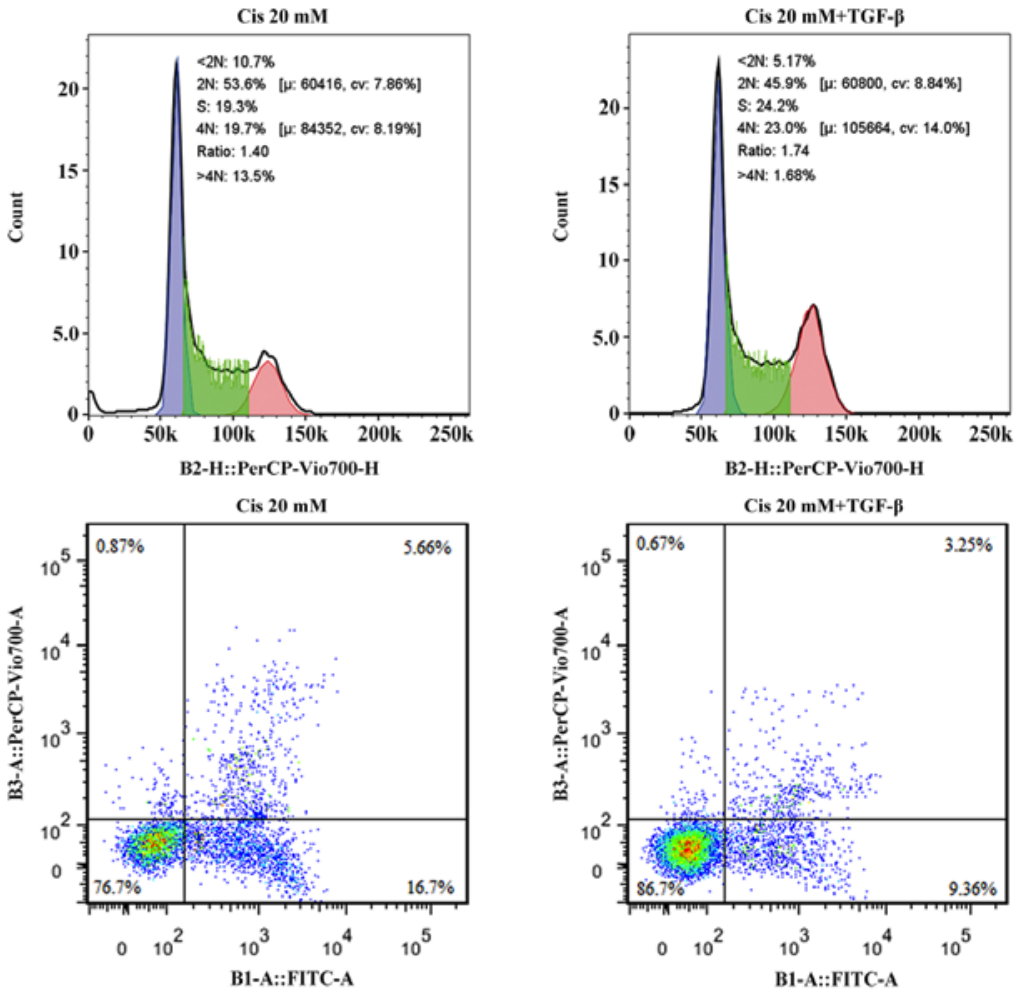

D
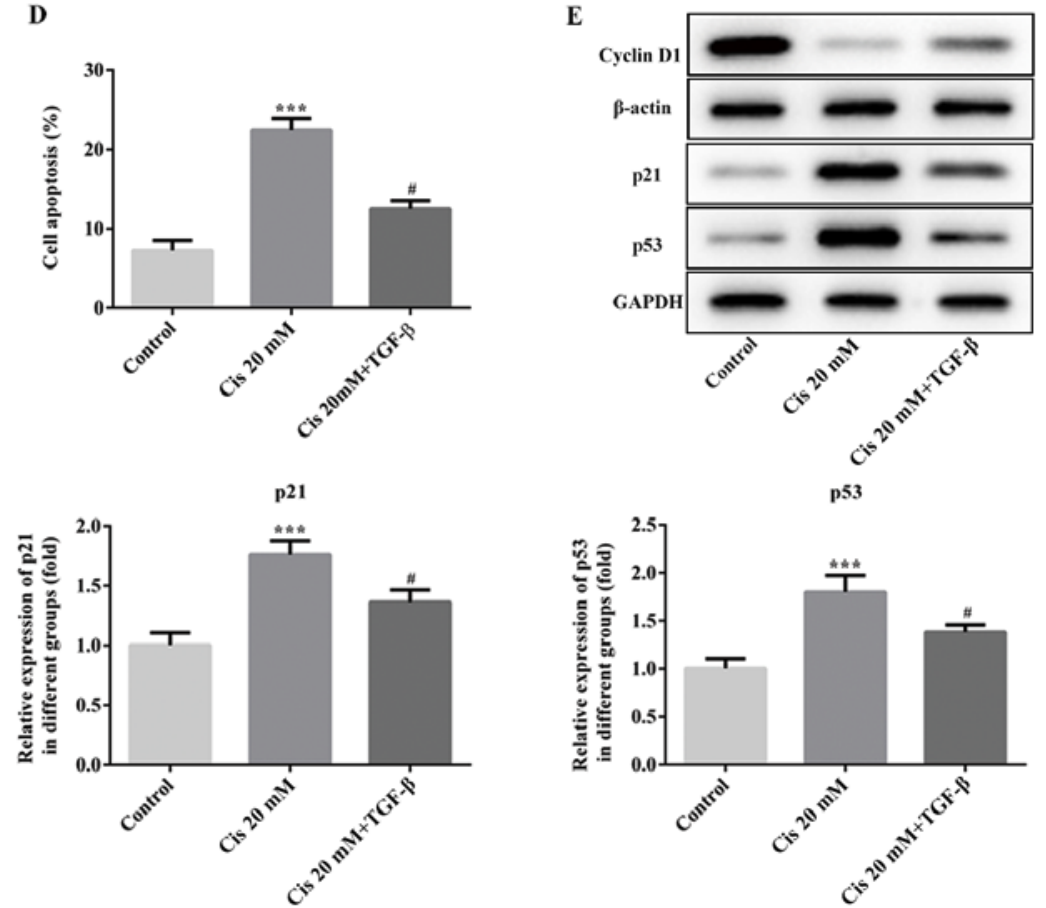

Figure 2. Cell cycle distribution and expression of cyclin D1, p53 and p21 following treatment of ESCC cells with Cis or Cis plus TGF- $\beta$. (A) Cell cycle distribution and (B) cell apoptosis were measured by flow cytometry. (C) Cell cycle distribution and (D) cell apoptotic rate with Cis or Cis plus TGF- $\beta$ were quantified. (E) Western blot analysis of cyclin D1, p53 and p21. (F) Relative expression levels of cyclin D1, p53 and p21. ${ }^{* *} \mathrm{P}<0.05,{ }^{* * *} \mathrm{P}<0.001 \mathrm{vs}$. control; ${ }^{\#} \mathrm{P}<0.05$, ${ }^{\# \#} \mathrm{P}<0.01$ vs. Cis $20 \mathrm{mM}$. ESCC, esophageal squamous cell carcinoma; TGF- $\beta$, transforming growth factor- $\beta$; Cis, cisatracurium.

ESCC, which is particularly common in China (25). Despite the advances in surgery, chemotherapy and radiotherapy over the past decades, current medical interventions are not satisfactory in the clinical setting, and the overall prognosis of ESCC is poor due to the late diagnosis and lack of effective therapies $(26,27)$. Anesthesia plays a crucial role in surgery, ensuring patient safety (28); however, to the best of our knowledge, there are very few studies on the effects of anesthetic agents on cancer. Emerging evidence supports the hypothesis that certain anesthetic drugs may affect cancer cell proliferation, angiogenesis and apoptosis (29). In the present study, the results demonstrated that Cis inhibited the proliferation, invasion, migration and EMT induced by TGF- $\beta$ in ESCC cells.

The cell cycle is a well-regulated intracellular program that maintains normal cell division and growth; however, deregulation of the cell cycle machinery frequently occurs 

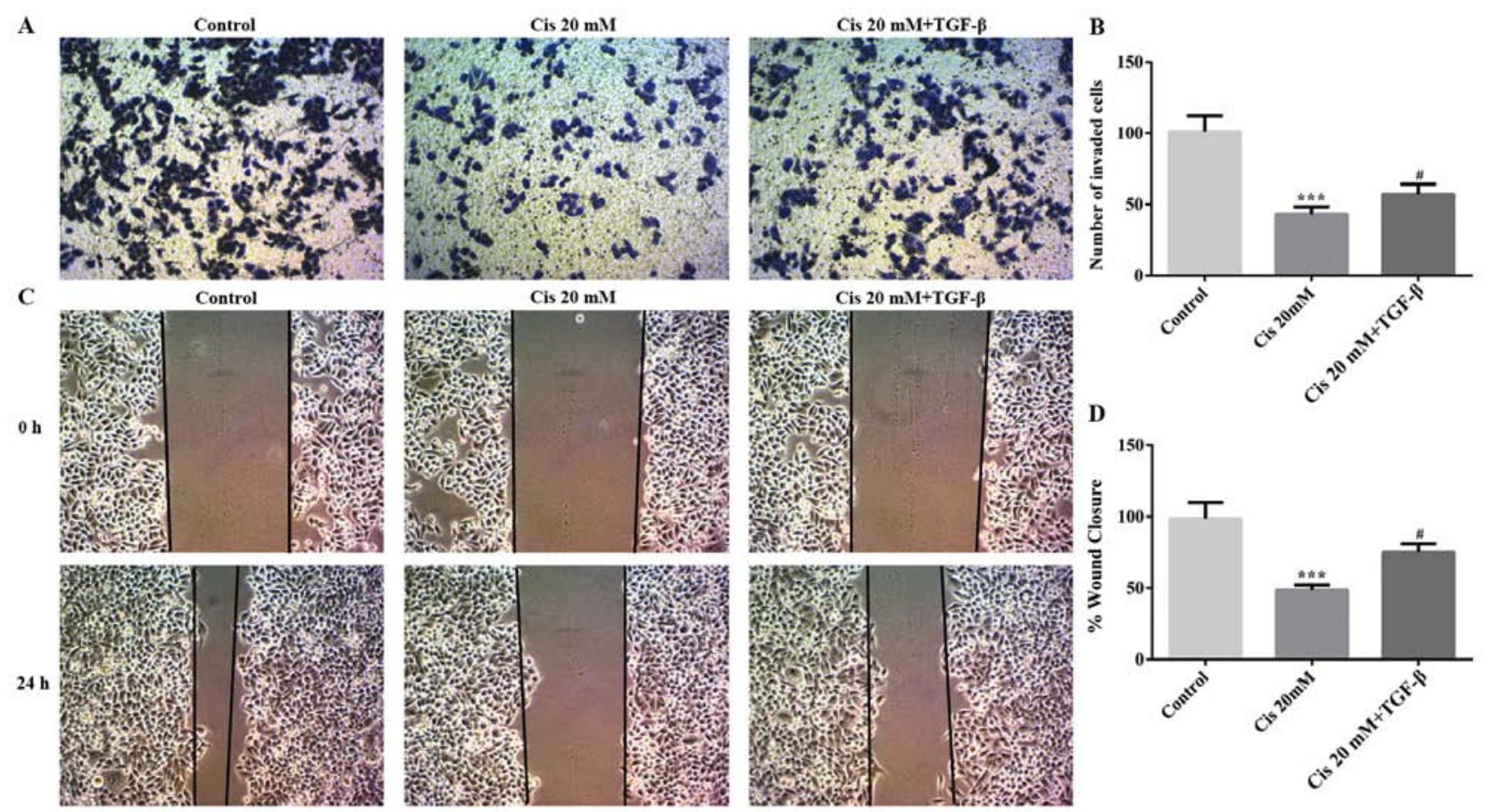

Figure 3. Invasion and migration of ESCC cells following treatment with Cis or Cis plus TGF- $\beta$. (A) Invasion activity of ESCC cells was evaluated following treatment with Cis or Cis plus TGF- $\beta$. Magnification, $\mathrm{x} 20$. (B) Number of invaded cells following treatment with Cis or Cis plus TGF- $\beta$. (C) Migratory activity of ESCC cells was evaluated with a scratch assay at different time points. Magnification, x20. (D) Number of migrated cells following treatment with Cis or Cis plus TGF- $\beta .{ }^{* * * *} \mathrm{P}<0.001$ vs. control; ${ }^{*} \mathrm{P}<0.05$ vs. Cis $20 \mathrm{mM}$. Scale bar, $200 \mu \mathrm{m}$. ESCC, esophageal squamous cell carcinoma; TGF- $\beta$, transforming growth factor- $\beta$; Cis, cisatracurium.
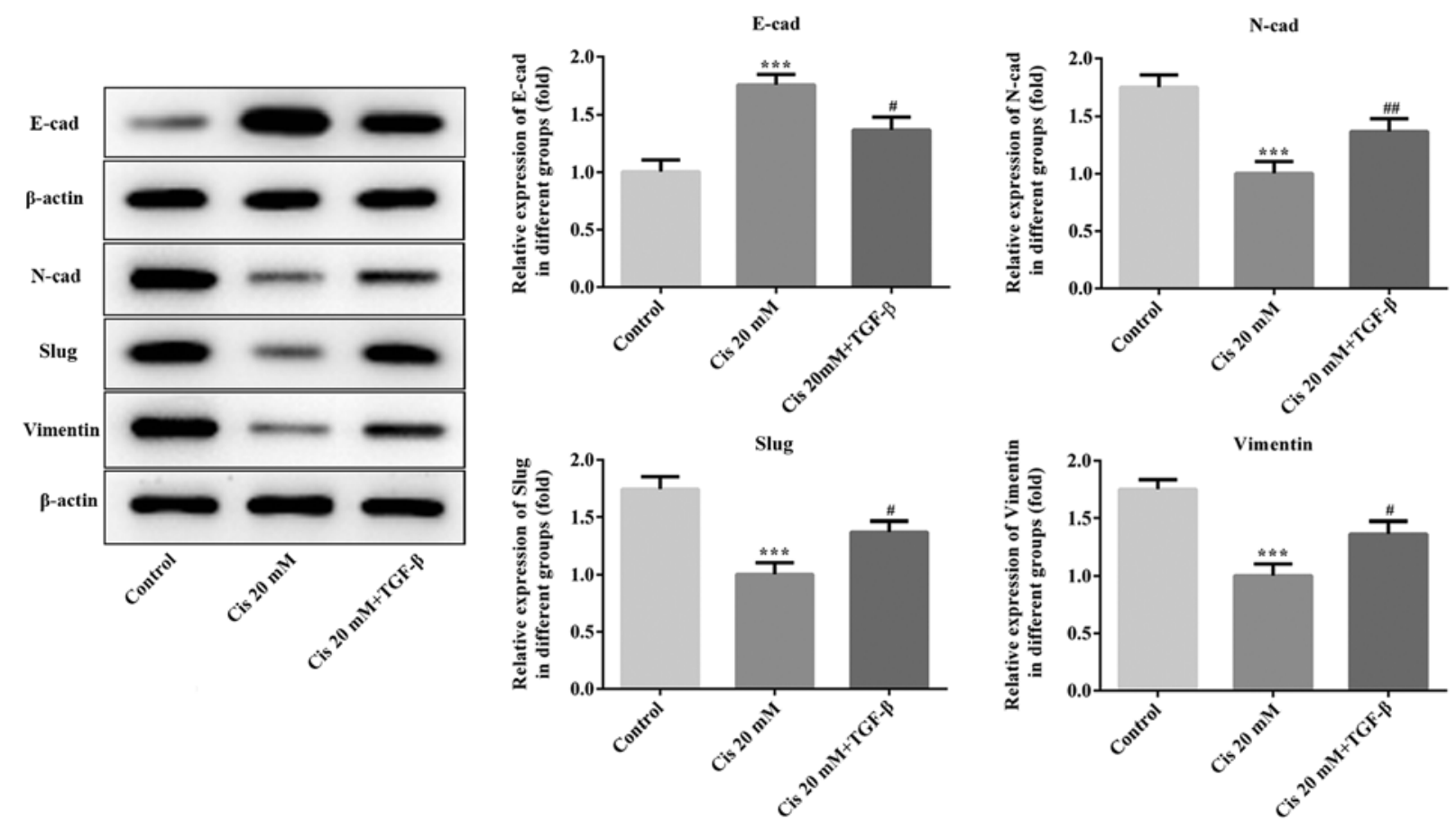

Figure 4. Protein expression levels of E-cadherin, N-cadherin, Slug and Vimentin following ESCC cell treatment with Cis or Cis plus TGF- $\beta$ were measured using western blot analysis. ${ }^{* * *} \mathrm{P}<0.001$ vs. control; ${ }^{\#} \mathrm{P}<0.05,{ }^{\# \#} \mathrm{P}<0.01$ vs. Cis $20 \mathrm{mM}$. ESCC, esophageal squamous cell carcinoma; TGF- $\beta$, transforming growth factor- $\beta$; Cis, cisatracurium.

various human malignancies, promoting abnormal and uncontrollable cell growth, as well as acquisition of aggressive metastatic features (30). Cyclin D1 is known to regulate transition through the G1-S phase $(31,32)$. During G1 phase arrest, cyclin-dependent kinase inhibitors, including p21, bind to cyclin complexes, thereby inhibiting cell proliferation (33). Previous studies have revealed that the transcription factor cellular tumor antigen p53 regulates the expression of 
numerous genes involved in the cell cycle and induces cell cycle arrest $(8,34)$. p21, a general G1 phase cell cycle inhibitor, was the first p53-effector gene to be identified $(35,36)$. In the present study, the proliferation of ESCC cells was inhibited, accompanied a decrease in cyclin D1 expression and increase in $\mathrm{p} 53$ and $\mathrm{p} 21$ expression following treatment with Cis compared with the control group. However, after exposure to both Cis and TGF- $\beta$, there was a promotion of ESCC cell proliferation and the expression of cyclin D1, whereas the opposite results were observed for $\mathrm{p} 53$ and $\mathrm{p} 21$ with Cis treatment alone.

Mounting evidence has demonstrated that the TGF- $\beta /$ Smad pathway is implicated in the progression of cancer through regulation of the expression of related genes (37-39). TGF- $\beta$ has the ability to induce invasion, migration and EMT in a number of cancer cell types, including glioblastoma and breast cancer $(40,41)$. Novel TGF- $\beta 1$ inhibitors have been used to block TGF- $\beta 1$-induced EMT in human A549 lung cancer cells (42). A recent study reported that CD82 suppresses invasion and metastasis of ESCC via TGF- $\beta 1$ (43). In addition, accumulating evidence has demonstrated that inhibition of EMT contributes to improved treatment and prognosis of ESCC (44-46). The findings of the present study revealed that treatment with Cis downregulated the expression of TGF- $\beta$ and phosphorylation of Smad2/3. In addition, Cis inhibited invasion and migration of ESCC cells. Furthermore, Cis increased the expression of E-cad and decreased $\mathrm{N}$-cad, Slug and Vimentin expression, which are well-established EMT-associated proteins. These results indicated that Cis inhibited EMT in ESCC cells. The aforementioned findings were in accordance with those of previous studies using other anesthetics, such as rocuronium and fentanyl $(20,47)$.

In conclusion, this mechanistic study is, to the best of our knowledge, the first to reveal that Cis suppresses the proliferation, invasion, migration and EMT in ESCC cells, which may prove to be of value in guiding clinical diagnosis and treatment. However, the use of a single ESCC cell line is a limitation of this study and therefore, a comprehensive analysis of more cell lines is required in the future to understand the effects of Cis in ESCC.

\section{Acknowledgements}

Not applicable.

\section{Funding}

No funding was received.

\section{Availability of data and materials}

The analyzed data sets generated during the present study are available from the corresponding author on reasonable request.

\section{Authors' contributions}

WL wrote the manuscript, analyzed the data and revised the manuscript. JW and SZ searched the literature, designed the study and performed experiments. All authors read and approved the final manuscript.

\section{Ethics approval and consent to participate}

Not applicable.

\section{Patients consent for publication}

Not applicable.

\section{Competing interests}

The authors declare that they have no competing interests.

\section{References}

1. Siegel RL, Miller KD and Jemal A: Cancer statistics, 2018. CA Cancer J Clin 68: 7-30, 2018.

2. Chen W, Zheng R, Baade PD, Zhang S, Zeng H, Bray F, Jemal A, Yu XQ and He J: Cancer statistics in China, 2015. CA Cancer J Clin 66: 115-132, 2016.

3. D'Amico TA: Outcomes after surgery for esophageal cancer. Gastrointest Cancer Res 1: 188-196, 2007.

4. Dotto GP and Rustgi AK: Squamous cell cancers: A unified perspective on biology and genetics. Cancer Cell 29: 622-637, 2016.

5. Suo C, Yang Y, Yuan Z, Zhang T, Yang X, Qing T, Gao P, Shi L, Fan M, Cheng H, et al: Alcohol intake interacts with functional genetic polymorphisms of aldehyde dehydrogenase (ALDH2) and alcohol dehydrogenase (ADH) to increase esophageal squamous cell cancer risk. J Thorac Oncol 14: 712-725, 2019.

6. Yang PW, Hsieh MS, Chang YH, Huang PM and Lee JM: Genetic polymorphisms of ATG5 predict survival and recurrence in patients with early-stage esophageal squamous cell carcinoma. Oncotarget 8: 91494-91504, 2017.

7. Cheng YW, Liao LD, Yang Q, Chen Y, Nie PJ, Zhang XJ, Xie JJ, Shan BE, Zhao LM, Xu LY and Li EM: The histone deacetylase inhibitor panobinostat exerts anticancer effects on esophageal squamous cell carcinoma cells by inducing cell cycle arrest. Cell Biochem Funct 36: 398-407, 2018.

8. Kastan MB, Canman CE and Leonard CJ: P53, cell cycle control and apoptosis: Implications for cancer. Cancer Metastasis Rev 14: 3-15, 1995.

9. Wang Z, Zhang Y, Gu JJ, Davitt C, Reeves R and Magnuson NS: Pim-2 phosphorylation of p21(Cip1/WAF1) enhances its stability and inhibits cell proliferation in HCT116 cells. Int J Biochem Cell Biol 42: 1030-1038, 2010.

10. Huang H, Han Y, Yang X, Li M, Zhu R, Hu J, Zhang X, Wei R, Li K and Gao R: HNRNPK inhibits gastric cancer cell proliferation through $\mathrm{p} 53 / \mathrm{p} 21 / \mathrm{CCND} 1$ pathway. Oncotarget 8 : 103364-103374, 2017.

11. Ghasri P, Admani S, Petelin A and Zachary CB: Treatment of actinic cheilitis using a 1,927-nm thulium fractional laser. Dermatol Surg 38: 504-507, 2012.

12. Quan J, Elhousiny M, Johnson NW and Gao J: Transforming growth factor- $\beta 1$ treatment of oral cancer induces epithelial-mesenchymal transition and promotes bone invasion via enhanced activity of osteoclasts. Clin Exp Metastasis 30: 659-670, 2013.

13. Creighton CJ, Chang JC and Rosen JM: Epithelial-mesenchymal transition (EMT) in tumor-initiating cells and its clinical implications in breast cancer. J Mammary Gland Biol Neoplasia 15: 253-260, 2010.

14. Kang Y and Massague J: Epithelial-mesenchymal transitions: Twist in development and metastasis. Cell 118: 277-279, 2004.

15. Thiery JP, Acloque H, Huang RY and Nieto MA: Epithelial-mesenchymal transitions in development and disease. Cell 139: 871-890, 2009.

16. Bai X, Li YY, Zhang HY, Wang F, He HL, Yao JC, Liu L and Li SS: Role of matrix metalloproteinase-9 in transforming growth factor- $\beta 1$-induced epithelial-mesenchymal transition in esophageal squamous cell carcinoma. Onco Targets Ther 10: 2837-2847, 2017.

17. Zhang C, Hao Y, Wang Y, Xu J, Teng Y and Yang X: TGF- $\beta$ /SMAD4-regulated LncRNA-LINP1 inhibits epithelial-mesenchymal transition in lung cancer. Int J Biol Sci 14: $1715-1723,2018$. 
18. Li F, Shi J, Xu Z, Yao X, Mou T, Yu J, Liu H and Li G: S100A4-MYH9 Axis promote migration and invasion of gastric cancer cells by inducing TGF- $\beta$-mediated epithelial-mesenchymal transition. J Cancer 9: 3839-3849, 2018.

19. Wu X, Zhao J, Ruan Y, Sun L, Xu C and Jiang $H$ Sialyltransferase ST3GAL1 promotes cell migration, invasion, and TGF- $\beta 1$-induced EMT and confers paclitaxel resistance in ovarian cancer. Cell Death Dis 9: 1102, 2018.

20. Jiang A, Zhao H, Cai J and Jiang WG: Possible effect of muscle-relaxant anaesthetics on invasion, adhesion and migration of breast cancer cells. Anticancer Res 36: 1259-1265, 2016.

21. Xu YB, Du QH, Zhang MY, Yun P and He CY: Propofol suppresses proliferation, invasion and angiogenesis by down-regulating ERK-VEGF/MMP-9 signaling in Eca-109 esophageal squamous cell carcinoma cells. Eur Rev Med Pharmacol Sci 17: 2486-2494, 2013.

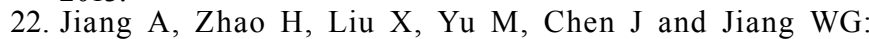
Comparison of different muscle-relaxant anesthetics on growth migration and invasion of gastric cancer cells. Anticancer Res 37: 4371-4378, 2017.

23. Yabasin IB, Sanches JGP, Ibrahim MM, Huidan J, Williams W, Lu ZL and Wen Q: Cisatracurium retards cell migration and invasion upon upregulation of $\mathrm{p} 53$ and inhibits the aggressiveness of colorectal cancer. Front Physiol 9: 941, 2018.

24. Yabasin IB Lu Z,Yu JC: Cisatracurium-induced proliferation impairment and death of colorectal cancer cells, HCT116 is mediated by $\mathrm{p} 53$ dependent intrinsic apoptotic pathway in vitro. Biomed Pharmacother 43: 320-329,2017.

25. Parkin DM, Bray F, Ferlay J and Pisani P: Global cancer statistics, 2002. CA Cancer J Clin 55: 74-108, 2005.

26. Matsuda S, Takeuchi H, Kawakubo H, Ando N and Kitagawa $\mathrm{Y}$ : Current advancement in multidisciplinary treatment for resectable cStage II/III esophageal squamous cell carcinoma in Japan. Ann Thorac Cardiovasc Surg 22: 275-283, 2016.

27. Baba Y, Watanabe M, Yoshida $\mathrm{N}$ and Baba $\mathrm{H}$ : Neoadjuvant treatment for esophageal squamous cell carcinoma. World $\mathrm{J}$ Gastrointest Oncol 6: 121-128, 2014.

28. Ciechanowicz SJ and Ma D: Anaesthesia for oncological surgery-can it really influence cancer recurrence? Anaesthesia 71: 127-131, 2016

29. Santamaria LB, Schifilliti D, La Torre D and Fodale V: Drugs of anaesthesia and cancer. Surg Oncol 19: 63-81, 2010.

30. Besson A, Dowdy SF and Roberts JM: CDK inhibitors: Cell cycle regulators and beyond. Dev Cell 14: 159-169, 2008.

31. Sherr CJ and Roberts JM: CDK inhibitors: positive and negative regulators of G1-phase progression. Genes Dev 13: 1501-1512, 1999.

32. Santarius T, Shipley J, Brewer D, Stratton MR and Cooper CS A census of amplified and overexpressed human cancer genes. Nat Rev Cancer 10: 59-64, 2010.

33. Shen G, Xu C, Chen C, Hebbar V and Kong AN: p53-independent G1 cell cycle arrest of human colon carcinoma cells HT-29 by sulforaphane is associated with induction of p21CIP1 and inhibition of expression of cyclin D1. Cancer Chemother Pharmacol 57: 317-327, 2006

34. Mo J, Lin M, He B, Tan K, Jin C, Jiang H, Pan X and Lin W: Recombinant human adenovirus-p53 improves the outcome of mid-late stage pancreatic cancer via arterial infusion. Oncol Lett 14: 6829-6832, 2017

35. Huang X, Qiao Y, Zhou Y, Ruan Z, Kong Y, Li G, Xie X and Zhang J: Ureaplasma spp. Lipid-associated membrane proteins induce human monocyte U937 cell cycle arrest through p53-independent p21 pathway. Int J Med Microbiol 308: 819-828, 2018.
36. Wang Y, Qiu C, Lu N, Liu Z, Jin C, Sun C, Bu H, Yu H, Dongol S and Kong B: FOXD1 is targeted by miR-30a-5p and miR-200a-5p and suppresses the proliferation of human ovarian carcinoma cells by promoting p21 expression in a p53-independent manner. Int J Oncol 52: 2130-2142, 2018.

37. Liu L, Liu H, Zhou Y, He J, Liu Q, Wang J, Zeng M, Yuan D, Tan F, Zhou Y, et al: HLTF suppresses the migration and invasion of colorectal cancer cells via TGF $\beta /$ SMAD signaling in vitro. Int J Oncol 53: 2780-2788, 2018.

38. Liu Y, Wang JX, Huang D, Wang B, Li LL, Li XX, Ni P, Dong XL, Xia W, Yu CX, et al: PMLIV overexpression promotes TGF- $\beta$-associated epithelial-mesenchymal transition and migration in MCF-7 cancer cells. J Cell Physiol 233: 9575-9583, 2018.

39. Li L, Lv Y and Yan D: Inhibition of Ep3 attenuates migration and promotes apoptosis of non-small cell lung cancer cells via suppression of TGF- $\beta /$ Smad signaling. Oncol Lett 16: 5645-5654, 2018.

40. Luo D, Xu X, Li J, Chen C, Chen W, Wang F, Xie Y and Li F: The PDK1/c-Jun pathway activated by TGF- $\beta$ induces EMT and promotes proliferation and invasion in human glioblastoma. Int J Oncol 53: 2067-2080, 2018.

41. Wu W, Chen F, Cui X, Yang L, Chen J, Zhao J, Huang D, Liu J, Yang L, Zeng J, et al: LncRNA NKILA suppresses TGF- $\beta$-induced epithelial-mesenchymal transition by blocking NF- $\kappa$ B signaling in breast cancer. Int J Cancer 143: 2213-2224, 2018.

42. Ko H, So Y, Jeon H, Jeong MH, Choi HK, Ryu SH, Lee SW, Yoon HG and Choi KC: TGF-B1-induced epithelial-mesenchymal transition and acetylation of Smad2 and Smad3 are negatively regulated by EGCG in human A549 lung cancer cells. Cancer Lett 335: 205-213, 2013.

43. Zeng TD, Zheng B, Zheng $\mathrm{W}$ and Chen C: CD82/KAI1 inhibits invasion and metastasis of esophageal squamous cell carcinoma via TGF-ß1. Eur Rev Med Pharmacol Sci 22: 5928-5937, 2018.

44. Thar Min AK, Okayama H, Saito M, Ashizawa M, Aoto K, Nakajima T, Saito K, Hayase S, Sakamoto W, Tada T, et al: Epithelial-mesenchymal transition-converted tumor cells can induce T-cell apoptosis through upregulation of programmed death ligand 1 expression in esophageal squamous cell carcinoma. Cancer Med 2018 (Epub ahead of print).

45. Hong D, Liu T, Huang W, Liao Y, Wang L, Zhang Z, Chen H, Zhang X and Xiang Q: Gremlin1 delivered by mesenchymal stromal cells promoted epithelial-mesenchymal transition in human esophageal squamous cell carcinoma. Cell Physiol Biochem 47: 1785-1799, 2018.

46. Sato F, Kubota Y, Natsuizaka M, Maehara O, Hatanaka Y, Marukawa K, Terashita K, Suda G, Ohnishi S, Shimizu Y, et al: EGFR inhibitors prevent induction of cancer stem-like cells in esophageal squamous cell carcinoma by suppressing epithelial-mesenchymal transition. Cancer Biol Ther 16: 933-940, 2015.

47. Wang N, Zhang Z and Lv J: Fentanyl inhibits proliferation and invasion via enhancing miR-302b expression in esophageal squamous cell carcinoma. Oncol Lett 16: 459-466, 2018.

This work is licensed under a Creative Commons Attribution-NonCommercial-NoDerivatives 4.0 International (CC BY-NC-ND 4.0) License. 